\title{
A STUDY ON THE VARIATIONS IN CYSTIC DUCT: CLINICAL AND EMBRYOLOGICAL EVALUATION
}

\author{
Sirisha. V ${ }^{1}$, Udaya Kumar. P ${ }^{2}$, Naveen Kumar. B ${ }^{2}$, Kalpana. T ${ }^{2}$. \\ ${ }^{* 1}$ Assistant Professor, Department of Anatomy, Mamata Medical College, Khammam, India. \\ ${ }^{2}$ Associate Professor, Department of Anatomy, Mamata Medical College, Khammam, India.

\section{ABSTRACT}

Introduction: Cystic duct connects neck of the gallbladder with the common hepatic duct. It conveys bile from the gallbladder to the common hepatic duct. Gallbladder and cystic duct are developed from cystic bud which has been derived from the hepatic diverticulum. Variations in the cystic duct are not uncommon. The success of surgical procedures on gallbladder and hepatic apparatus depends on the knowledge of the normal anatomy and their variations.

Materials and Methods: The present study was done on 52 adult cadaveric specimens in the Department of Anatomy, Mamata Medical College, Khammam, Telangana state.

Observations: During the study, different variations regarding cystic duct were found in 27 [51.92\%] specimens. Variations like double cystic duct, absent cystic duct, accessory ducts and variations in the termination of cystic duct into the common hepatic duct [right side, anterior, left side] were observed.

Conclusion: The knowledge of variations in cystic duct anatomy is necessary for surgeons while conducting surgeries like cholecystectomy. During cholecystectomy, there is a possibility of complications in cases where variations are overlooked.

KEY WORDS: Cystic duct, Common hepatic duct, Cystic bud, Cholecystectomy.

Address for Correspondence: Dr. Udaya Kumar P, Associate Professor, Department of Anatomy, Mamata Medical College, Rotary Nagar, Khammam. Telangana - 507002, India.

Mobile No: 0913300191 E-Mail: udaymmc7@gmail.com

\section{Access this Article online}

\section{Quick Response code}

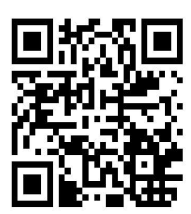

DOI: $10.16965 /$ ijar.2017.319

Web site: International Journal of Anatomy and Research ISSN 2321-4287

www.ijmhr.org/ijar.htm

Received: 23 June 2017

Peer Review: 24 June 2017

Revised: None
Accepted: 03 Aug 2017

Published (O): 31 Aug 2017

Published (P): 31 Aug 2017

\section{INTRODUCTION}

Cystic duct $[C D]$, in our body, connects the gall bladder [GB] with common hepatic duct [CHD]. It arises from neck of the gall bladder, passes upwards and backwards towards left to join the common hepatic duct. It usually joins hepatic duct on the right side to form the bile duct [1]. It is $2-3 \mathrm{~cm}$ long. It allows bi-directional flow of bile. During $4^{\text {th }}$ week of intra-uterine life, liver and biliary apparatus develops from an endodermal diverticulum called hepatic diverticulum. The hepatic diverticulum has two parts, cranial and caudal. The cranial part develops into liver proper. The caudal part forms the gallbladder and its stalk forms the cystic duct. Initially the lumen is occluded. Bile formation begins in the liver during $12^{\text {th }}$ week [2]. By the end of the $12^{\text {th }}$ week, biliary tract becomes canalised to carry the bile produced by the liver $[1,3,4]$.

Variations in the cystic duct and presence of accessory hepatic segmental ducts are not uncommon. They may be asymptomatic but are clinically significant [2]. They become symptomatic under pathological conditions and may pose 
danger during cholecystectomy. [3]. The accessory ducts are narrow channels running from the right lobe of the liver into the anterior surface of the gallbladder [2]. They may join CHD along with $\mathrm{CD}$ or may directly drain into CD [5]. Sometimes cystic duct may open into the accessory duct instead of common hepatic duct [2]. The success of the surgical procedures on gallbladder and biliary apparatus depends on the knowledge of the normal anatomy and variations.

Aims \& Objectives: To study the variations in the cystic duct anatomy, its termination and the possible embryological causes for the variations. To discuss the probable complications caused during cholecystectomy due to these variations.

\section{MATERIALS AND METHODS}

The present study was conducted in 52 adult cadaveric specimens in the Department of Anatomy, Mamata Medical College, Khammam over a period of 4 years. The abdomen was dissected by opening the anterior abdominal wall. The liver and gallbladder was exposed and the cystic duct was traced. The normal course and abnormalities of cystic duct were observed. Deformed and pathological specimens were excluded from the study.

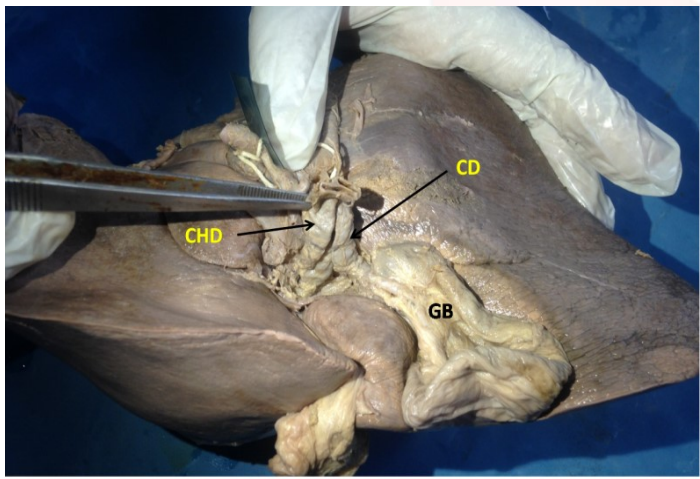

Fig No. 1: showing long cystic duct coursing along with common hepatic duct to certain distance. Both are enclosed in a common fibrous sheath [which was removed], GB-gallbladder, CD-cystic duct, CHD-common hepatic duct

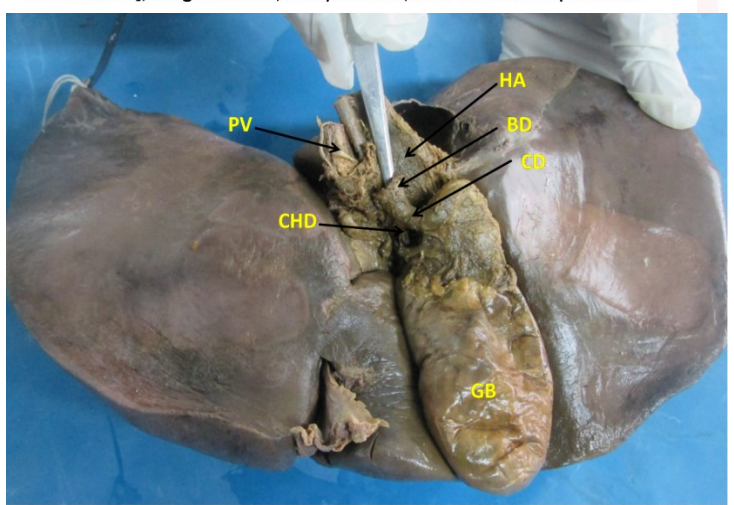

Fig No. 2: showing short cystic duct. CD-cystic duct, GB-gallbladder, HA-hepatic artery, PV-portal vein, CHD-common hepatic duct, BD-bile duct

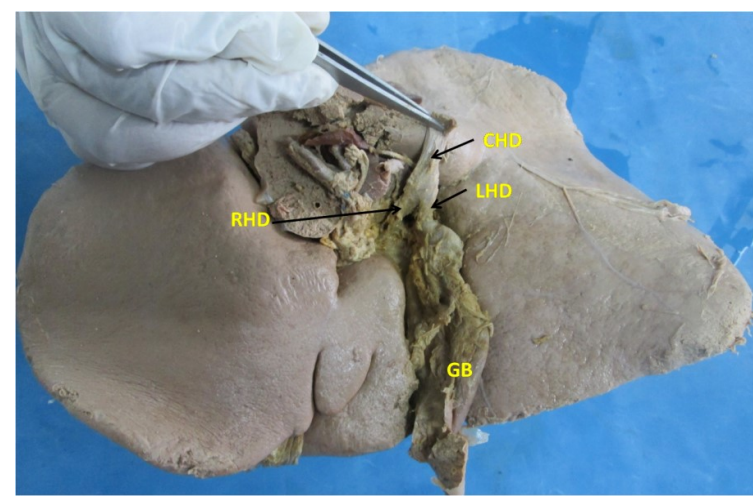

Fig No. 3: showing absent cystic duct and gallbladder directly opening into left hepatic duct. GB-gallbladder, CHD-common hepatic duct, LHD-left hepatic duct, RHD-right hepatic duct

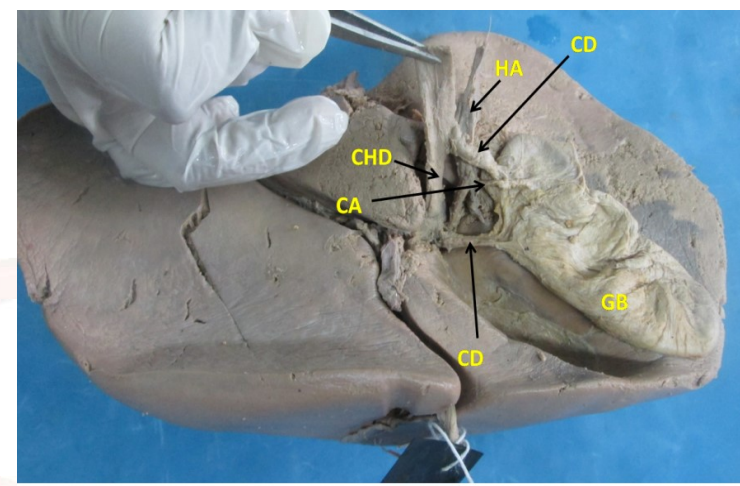

Fig No. 4: showing double cystic duct. One joining the proximal part of CHD and the other joining in the distal part. GB-gallbladder, CD-cystic duct, CAcystic artery, CHD-common bile duct, HA-hepatic artery

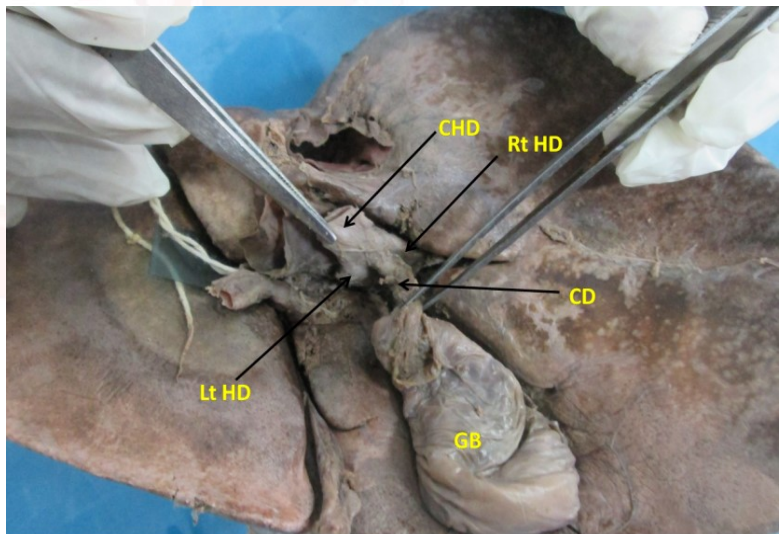

Fig No. 5 - showing the cystic duct opening at the junction of formation of common hepatic duct. GB- Gallbladder, CD-Cystic duct, CHD-Common hepatic duct, It HD-Left hepatic duct, rt HD- right hepatic duct

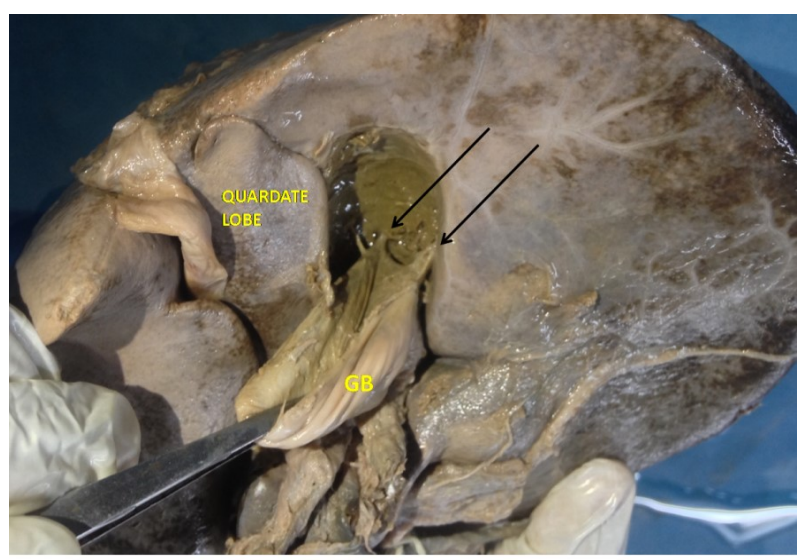

Fig No. 6: - showing segmental ducts directly opening into gallbladder from inferior surface of the liver GB-Gallbladder, arrows indicate segmental ducts 


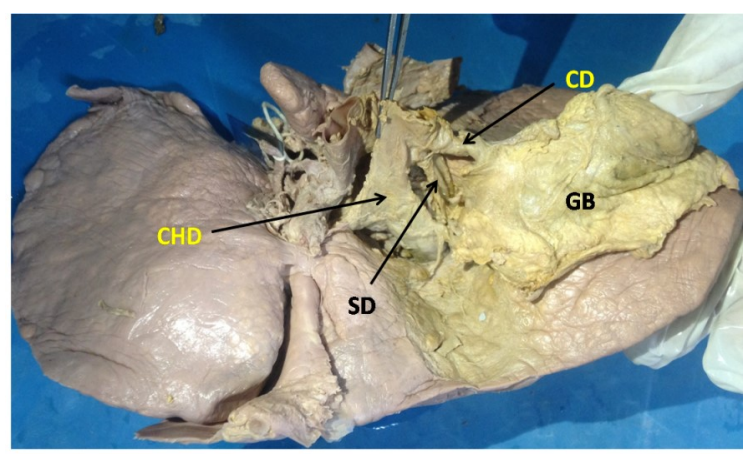

Fig No. 7: $\mathrm{CD}$ opening along with a segmental duct of right lobe. GBgallbladder, SD - Segmental duct, CD-cystic duct, CHD-common hepatic duct

\section{OBSERVATIONS}

The different variations regarding cystic duct were found in 27 [51.92\%] specimens. The observations are categorised into different groups. (I) Presence or absence of cystic duct. (II) Number of cystic ducts. (III) Opening of the cystic duct. (IV) Presence of accessory ducts. The variations observed were represented in tabular forms [Table $1 \& 2$ ]. The results are compared with observations of different authors [Table-3].

Table 1: Showing the type of variations of cystic duct.

\begin{tabular}{|c|c|c|c|c|}
\hline Sl. No. & Type of variation & Number & Percentage & Remarks \\
\hline 1 & Long cystic duct & 6 & 11.53 & Length range $-4.5 \mathrm{~cm}$ to $6.1 \mathrm{~cm}$ \\
\hline 2 & Short cystic duct & 2 & 3.84 & Length $-0.75 \mathrm{~cm} \& 1 \mathrm{~cm}$ \\
\hline 3 & Absent cystic duct & 1 & 1.92 & \\
\hline 4 & Double cystic duct & 1 & 1.92 & \\
\hline
\end{tabular}

Table 2: Showing the variation in the termination of cystic duct.

\begin{tabular}{|c|c|c|c|}
\hline Sl. No. & Termination of cystic duct & Number & Percentage \\
\hline $\mathbf{1}$ & CHD - right side & 35 & 67.3 \\
\hline $\mathbf{2}$ & CHD - anterior aspect & 11 & 21.15 \\
\hline $\mathbf{3}$ & CHD - left side & 2 & 3.84 \\
\hline $\mathbf{4}$ & At the junction of formation of CHD & 2 & 3.84 \\
\hline $\mathbf{5}$ & Right hepatic duct & 1 & 1.92 \\
\hline $\mathbf{6}$ & Left hepatic duct & 1 & 1.92 \\
\hline
\end{tabular}

Table 3: Showing the comparison of variation in the termination of cystic duct.

\begin{tabular}{|c|c|c|c|}
\hline Sl. No. & Termination of cystic duct & $\begin{array}{c}\text { Radha Sarawagiet al [18] } \\
\mathrm{n}=198\end{array}$ & Present study n=52 \\
\hline 1 & CHD- right side & 51.5 & 67.3 \\
\hline 2 & CHD - anterior aspect & 2 & 21.15 \\
\hline 3 & CHD - left side & 16.1 & 3.84 \\
\hline 4 & At the junction of formation of CHD & - & 3.84 \\
\hline 5 & Right hepatic duct & 0.5 & 1.92 \\
\hline 6 & Left hepatic duct & - & 1.92 \\
\hline
\end{tabular}

Long CD - $6(4.5 \mathrm{~cm}$ to $6.1 \mathrm{~cm})(11.53 \%)$ [Fig No. 1], Short CD - 2 [0.75 cm \& $1 \mathrm{~cm}](3.84 \%)$ [Fig No. 2], Absent CD - 1(1.92\%) [GB opening into the CHD anterior aspect] [Fig No. 3], Double
CD - 1 [Fig No. 4] [one opening into the middle part of CHD, the other into the proximal part], CD opening at the formation of CHD -2 [Fig No. 5], $\mathrm{CD}$ opening into $\mathrm{CHD}$ and segmental duct opening at a higher level - 1, Small GB with accessory ducts opening into $G B$ from under surface of liver -1 [Fig No. 6]. CD opening into right $\mathrm{HD}-2, \mathrm{CD}$ opening on right side of $\mathrm{CHD}-$ $35(67.3 \%), C D$ opening on the anterior aspect of CHD - 11(21.15\%), [Fig No. 2], CD opening on left side of $\mathrm{CHD}-2, \mathrm{CD}$ opening along with a segmental duct of right lobe -1 [Fig No. 7],

\section{DISCUSSION}

Various authors have studied and reported on various surgical complications due to cystic duct [CD] variations previously. The success of the surgical procedures on gallbladder [GB] and biliary apparatus depends on the knowledge of the normal anatomy and variations. Double cystic duct is one of rare variation which may occur due to the duplication of the stalk of the gallbladder diverticulum during development. The surgeons should explore further to look for the possible presence of double cystic duct or for the segmental ducts after ligation of the cystic duct during cholecystectomy. According to Tara L. Huston [6], the variant of double cystic duct is classified into a) $Y$ - type in which 2 cystic ducts meet to form a common channel, b) $\mathrm{H}$ type in which the accessory duct enters separately into the right, left or common hepatic duct [CHD] and c) The trabecular type, in which the accessory cystic duct enters the substance of the liver directly. In the present study the variant found was $\mathrm{H}$-type. Absent cystic duct is another rare variation which causes severe complications. So, the congenital absence of the CD necessitates open cholecystectomy [7]. Failed development of the proximal part of the gallbladder diverticulum results in agenesis of the cystic duct [8]. Chronic inflammatory changes of $G B$ may result in dilatation of $C D$ giving it an appearance of absent CD [8]. Low union of cystic duct with CHD results in short common bile duct.

The $C D$ and $C H D$ are held together by fibrous tissue making surgical clamping of $C D$ difficult. It also injures the CHD [5]. Ligation of the CD too close to the common bile duct can result in 
stricture of the latter. On the other hand, mistaking the cystic duct for the bile duct can result in inadvertent ligation or transection of the extrahepatic bile duct $[9,10]$. One of the postoperative complication of the long cystic duct is left out cystic duct stump, which might get inflamed or get dilated with mucous $[9,10,11]$. According to Shaw [12], long cystic duct is a common variation but it occurs in $11 \%$ individuals. In the present study, we observed $11.53 \%$ of long cystic ducts. The accessory ducts [Luschka's ducts] are narrow channels running from the right lobe of the liver into the anterior surface of the gallbladder [2]. They may join CHD along with $\mathrm{CD}$ or may directly drain into $\mathrm{CD}$ [5]. Sometimes cystic duct may open into the accessory duct instead of common hepatic duct [2].

These variations may occur due to disproportion in the growth rate of the individual parts of the biliary tract [8]. In the present study, it was observed the segmental ducts drained into gallbladder from under surface of liver and in some specimens segmental duct drained into hepatic duct from right lobe of liver. Surgeons should be cautious during cholecystectomy in order to prevent bile leakage from these segmental ducts. During laparoscopic cholecystectomy, dissection beyond the Calot's triangle should be meticulous enough to avoid the impending complication of bile leak [13].

Cystic duct terminating into one of the hepatic duct might be due to unusual absorption of the many small secondary branches which project from the various buddings of the hepatic diverticulum [14].

Magnetic resonance cholangio-pancreatography [MRCP] is a non-invasive technique followed nowadays. This technique provides high quality cross-sectional and projection images of the biliary tree, which are almost similar in appearance to the direct cholangiograms produced by Endoscopic retrograde cholangio-pancreatography [ERCP] or percutaneous trans-hepatic cholangiography $[10,11]$.

Imaging of the course of the cystic duct is possible in a high percentage of cases [15]. Preoperative evaluation of the extra-hepatic bile duct increases the surgeon's awareness of variants, especially in potentially difficult operative situations $[10,16,17]$.

Int J Anat Res 2017, 5(3.2):4308-12. ISSN 2321-4287

\section{CONCLUSION}

The knowledge of variations in cystic duct anatomy is necessary to the surgeons while conducting surgeries like cholecystectomy. During cholecystectomy, there is a possibility of complications in cases where variations are overlooked. Pre-operative evaluation through MRCP helps the surgeons to become aware of the variations.

\section{ACKNOWLEDGEMENTS}

Authors acknowledge the immense help received from the scholars whose articles are cited and included in references of this manuscript. The authors are also grateful to authors / editors / publishers of all those articles, journals and books from where the literature for this article has been reviewed and discussed.

\section{Conflicts of Interests: None}

\section{REFERENCES}

[1]. Susan Standring - Gray's Anatomy - The anatomical basis of clinical practice. $41^{\text {st }}$ ed. 2016, Elsevier, Pg.1052-54, 1173-78.

[2]. Keith L. Moore, T V N Persaud - The Developing Human: Clinically Oriented Embryology, $5^{\text {th }}$ ed., 1993, W. B. Saunders Company, Philadelphia; Pg.243.

[3]. T. W. Sadler - Langman's Medical Embryology, $12^{\text {th }}$ ed., 2013, Lippincott Williams \& Wilkins, New Delhi, Pg. 217-220

[4]. Datta A.K - Essentials of Embryology, 6 ${ }^{\text {th }}$ Ed. 2013. Current books international, Kolkata. Pg 131-33.

[5]. Keith L. Moore, Arthur F. Dalley, Anne M. R. Agur Moore Clinically Oriented Anatomy, $7^{\text {th }}$ ed., 2013, Lippincott Williams \& Wilkins, New Delhi, 277-278, 286-287.

[6]. Tara L. Huston, MD; Gregory F. Dakin, MD - Double cystic duct, Can J Surg, Vol. 51, No. 1, February 2008, E9-E10.

[7]. Sachin Patil et al - Congenital Absence of the Cystic Duct: A Rare but Significant Anomaly, Surgical Science, 2013, 4, 241-246

[8]. Yehuda Adam, William Metcalf - Absence of Cystic duct: A case report, the Embryology and the review of literature, Annals of Surgery, Dec 1966, vol. 164 [6]; 1056-1058.

[9]. Mary Ann Turner, Ann S. Fulcher-The Cystic Duct: Normal Anatomy and Disease Processes, RadioGraphics 2001; 21:3-22

[10]. Theodoros E. Pavlidis et al - Long, Parallel Cystic Duct in Laparoscopic Cholecystectomy for Acute Cholecystitis: the Role of Magnetic Resonance Cholangiopancreatography, JSLS (2008)12:407-409 407 
[11]. Arun Kumar S. Bilodi, Gangadhar MR - Cystic Duct Remnant Syndrome Associated with Symptomatic Dilatation of Cyst Duct, International Journal of Anatomical Sciences 2011, 2(2): 34-36

[12]. Shaw MJ, Dorsher PJ, Vennes JA - Cystic duct anatomy: an endoscopic perspective, Am J Gastroenterol. 1993 Dec;88(12):2102-6.

[13]. U. Parampalli, S. Helme, G. Asal and P. Sinha - Accessory cystic duct identification in laparoscopic cholecystectomy, Grand Rounds, 2008: Vol 8 pages 40-42.

[14]. A Ankouz, K Aittaleb, K Chakour - Anatomical variations of the cystic duct, OA Anatomy: 2014 Jun $10 ; 2(2): 14$.

[15]. Ausch C - Improving the safety of laparoscopic cholecystectomy: the routine use of preoperative magnetic resonance cholangiography, Surgical Endoscopy, 2005, 19(4):574-580
[16]. Alizadeh Shabanali, Darabi Mohammad Reza, Ahrari Khadijeh, Baazm Maryam, Alizadeh Mohammad Reza - double cystic duct, Int J Anat Res 2014, Vol 2(3):601-04.

[17]. Yun-Hua Wu, Zhi-Su Liu, Rekia Mrikhi, Zhong-Li Ai, Quan Sun, Gassimou Bangoura, Qun Qian, CongQing Jiang - Anatomical variations of the cystic duct: Two case reports, World J Gastroenterol 2008 January $7 ; 14(1)$ : 155-157.

[18]. Radha Sarawagi, Shyam Sundar, Sanjeev K. Gupta, and Sameer Raghuwanshi, "Anatomical Variations of Cystic Ducts in Magnetic Resonance Cholangiopancreatography and Clinical Implications," Radiology Research and Practice, vol. 2016, Article ID 3021484, 6 pages, 2016. doi:10.1155/2016/3021484

How to cite this article:

Sirisha. V, Udaya Kumar. P, Naveen Kumar. B, Kalpana. T. A STUDY ON THE VARIATIONS IN CYSTIC DUCT: CLINICAL AND EMBRYOLOGICAL EVALUATION. Int J Anat Res 2017;5(3.2):43084312. DOI: 10.16965/ijar.2017.319 